\title{
Identification of the homozygous recessive genotype for the deficiency of uridine monophosphate synthase in 35-day bovine embryos
}

\author{
R. D. Shanks, R. G. Popp, G. C. McCoy, D. R. Nelson and J. L. Robinson \\ University of Illinois, Departments of Animal Sciences \& Veterinary Clinical Medicine, \\ I32 Animal Sciences Laboratory, 1207 W. Gregory Drive, Urbana, IL 61801, USA
}

\begin{abstract}
Summary. Holstein-Friesian cattle heterozygous for the deficiency of uridine monophosphate (UMP) synthase have half-normal activity of UMP synthase. The homozygous recessive genotype would result in little or no activity, has not been observed among live animals and apparently leads to embryonic mortality at $\sim$ Day 40 of gestation. Activity of UMP synthase averaged $2.74 \pm 0.61$ units/mg protein for 19 obligatory normal embryos (from normal $\times$ normal matings). Activity for 18 embryos from heterozygote $\times$ heterozygote matings yielded three non-overlapping groups as follows: (i) five presumed normals with > two-thirds normal activity, (ii) ten apparent heterozygotes with one-third to two-thirds normal activity and (iii) three putative homozygous recessive embryos with < one-third normal activity. The distribution among these groups was consistent with the $1: 2: 1$ ratio expected for autosomal inheritance. Conception of embryos homozygous recessive for this disorder was demonstrated.
\end{abstract}

Kevwords: embryonic mortality; inherited disorder; uridine monophosphate synthase; embryo; cow

\section{Introduction}

It has long been recognized that genetic disorders contribute to embryonic and fetal mortality by causing reduced fertility in various species (Salisbury et al., 1977), but few examples of such disorders have been demonstrated because of the difficulty of studying a conceptus that is destined to be resorbed or aborted. One such example is the homozygous recessive genotype for the bovine deficiency of uridine-5'-monophosphate (UMP) synthase, which apparently results in embryonic mortality at $\sim$ Day 40 of gestation (Shanks \& Robinson, 1989). Mortality is attributed to reduced DNA and RNA synthesis as UMP synthase catalysed the de novo synthesis of pyrimidine nucleotides.

The deficiency of UMP synthase is inherited as an autosomal recessive among dairy cattle (Shanks et al., 1984). Heterozygotes, comprising 1-2\% of US Holsteins (Robinson et al., 1984; Shanks et al., 1987), have half the normal concentrations of the enzyme in various tissues (Harden \& Robinson, 1987). Erythrocyte UMP synthase activity is routinely used for identifying heterozygotes (Jones et al., 1986), with two-thirds of normal as the delimiter between normal and heterozygotes. Homozygous recessives are expected to have less than one-third normal activity, have not been observed in $>4000$ cattle tested and appear to die in utero. The evidence for embryonic mortality comes from matings between heterozygous females and males that resulted in 31 pregnancies diagnosed by rectal palpation at 1 -month after conception (Shanks \& Robinson, 1989). The outcome of these pregnancies was 9 normal calves born, 14 heterozygous calves born and 8 pregnancies not carried to term. The results were not different from the expectation of $1: 2: 1$, embryos not carried to term corresponding quantitatively to the missing genotype. Examination of 
reproduction records suggested that the embryos not carried to term were lost at $\sim$ Day 40 of gestation. More breeding services per calving were found from heterozygous $\times$ heterozygous matings than from normal $\times$ normal matings (Shanks, 1990).

While UMP synthase activity can be measured in 15-day embryos, variability among normal embryos at this age was extensive and precluded distinguishing between heterozygous and homozygous recessive embryos on the basis of activity (Robinson et al., 1989). The present study was initiated to assess whether UMP synthase values were sufficiently consistent in 35-day embryos to identify the three genotypes on the basis of activity levels. The ultimate goal was to demonstrate that homozygotes for this deficiency were indeed conceived and to assess whether their development was altered by 35 days of gestation. A preliminary report of this work has been made (Shanks et al., 1990).

\title{
Materials and Methods
}

\begin{abstract}
Animals. Procedures with animals were conducted at the dairy farm or veterinary clinic of the University of Illinois between September 1988 and February 1990. The protocol used was consistent with existing US regulations governing animal use and was approved by the Institutional Laboratory Animal Care Advisory Committee. Animals were identified as heterozygous on the basis of assay of erythrocyte UMP synthase (Jones et al., 1986); many animals were denoted normal if known heterozygotes were absent in their 3-generation pedigrees.
\end{abstract}

Superovulation. Donor females were superovulated by initiating, at Day $10 \pm 2$ of the oestrous cycle, intramuscular injections of follicle-stimulating hormone (pituitary, Schering, Kenilworth, NJ, USA), decreasing doses administered every $12 \mathrm{~h}$ over 5 days $(7 \cdot 50,6 \cdot 25,6 \cdot 25,5 \cdot 0,5 \cdot 0,3 \cdot 75,3 \cdot 75,2 \cdot 5$, and $2 \cdot 5 \mathrm{mg}$ of Armour Standard Equivalents, respectively) and, on the fourth day of the procedure, by giving two injections, $12 \mathrm{~h}$ apart, of cloprostenol (Estrumate, Haver, Mobay Corp., Shawnee, KS, USA; $750 \mu \mathrm{g}$ and $250 \mu \mathrm{g}$, respectively). The cows were inseminated two or three times at 12-h intervals, starting on the morning after the last injection. On Day $7 \pm 1$ of gestation, embryos were recovered from pregnant cows using Foley catheters and were examined microscopically to ensure that they were fertilized, intact, and normal for gestational age. One or two embryos were inserted non-surgically into each uterine horn of recipient animals with palpable corpora lutea; recipients had been synchronized with the donors by injections of cloprostenol $(750 \mu \mathrm{g})$ around Day 14 of their oestrous cycles. On Day $35 \pm 1$ of gestation, embryos were removed surgically from each uterine horn, accessed via a ventral midline abdominal incision while recipients were under general anaesthesia. Each embryo was separated from excessive membranes, photographed, placed in isotonic saline, and transported on ice to the laboratory for further study.

To obtain 18 embryos at Day 35 from heterozygote $\times$ heterozygote matings, four cows and two heifers were superovulated a total of 14 times and yielded 52 embryos that were transferred to recipients on Day 7 . To obtain obligatory normal embryos (from normal $\times$ normal matings), 11 cows were superovulated and produced 32 embryos that were transferred on Day 7; from these, 13 embryos were recovered on Day 35. Six additional embryos were from a cow that was superovulated and, in the absence of available recipients, carried the embryos without interruption until Day 35. Scheduling of surgical procedures required that some embryos be removed on Day 36 rather than Day $35 ; 3$ of 19 embryos from normal $\times$ normal matings and 14 of 18 embryos from heterozygote $\times$ heterozygote matings were removed one day later. Although younger embryos were slightly smaller, differences were not significant and all are referred to as 35 -day embryos hereafter.

Upon arrival in the laboratory, each embryo was weighed and cut transversely in half; each half was placed in $2 \mathrm{ml}$ $50 \mathrm{~mm}$ Tris ( $\mathrm{pH} 8.0$ ) and homogenized on ice for $15 \mathrm{~s}$ on speed setting 7 with a Polytron tissue homogenizer fitted with a $10 \mathrm{~mm}$ generator (Brinkmann Instruments, Westbury, NY, USA). Two $50 \mu$ portions of each half were immediately assayed for UMP synthase using the radioisotopic procedure described by Jones et al. (1986); activity units for embryos are expressed as $10^{-2} \mu \mathrm{mol}$ product formed/h. Correlation of specific activity between the two portions was 0.979 and between the two halves was 0.926 . Prompt assay for UMP synthase was essential, as freezing resulted in a loss of $70 \%$ of the activity. The remainder of each sample was frozen for subsequent assay of protein by the colorimetric, dye-binding method of Bradford (1976; Bio-Rad, Richmond, CA, USA).

Embryo measurement. Once all embryos had been collected and photographed, the photographs were enlarged 1.55-fold and placed in random order. The greatest length, which is equivalent to crown-to-rump length for embryos at this age (Winters et al., 1942), was the longest straight-line distance across the embryo as measured by calipers, normalized by a $5-\mathrm{cm}$ rule included in all photographs. The contour length (Winters et al., 1942) was the curvilinear distance from nose to tail, over the head and back, determined by placing pins at least every $5 \mathrm{~mm}$ and measuring the length with non-stretchable string with respect to the $5-\mathrm{cm}$ rule. Each measurement was determined independently from two sets of enlargements. All duplicate determinations agreed within $10 \%$ and the correlation between duplicates was 0.987 for greatest length and 0.966 for contour length.

Statistical analysis. Activity of UMP synthase, mass, greatest length and contour length were analysed by one-way analysis of variance for genotype where genotype corresponded to the four groups: (i) obligatorily normal, (ii) 
putative normal, (iii) putative heterozygote and (iv) putative homozygous recessive. Age of embryo ( 35 vs. 36 days) and interaction of age with genotype were fitted into preliminary models and were not detected as significant factors in view of our small samples. Effects of donors and recipients, beyond normal or heterozygous status for UMP synthase, were ignored in analysis because data were not balanced and large numbers of donors and recipients were used. While number of embryos per recipient merited consideration for inclusion in the model, only two recipients carried more than two embryos and all embryos were obligatorily normal; three embryos were removed from one recipient and six embryos were removed from one cow that carried them for the full 35 days. Effects of number of embryos per recipient within the obligatorily normal category will be discussed briefly.

\section{Results and Discussion}

In 35-day embryos from normal $\times$ normal matings, the mean UMP synthase activity \pm standard deviation was $2.74 \pm 0.61$ units/mg protein for a $22 \%$ coefficient of variation (Fig. 1). Because twothirds of normal is routinely used to distinguish normal from heterozygous (Jones et al., 1986) and only one value was below this threshold, a high degree of consistency is shown; only one embryo would be inappropriately classified. This embryo with the unexpectedly low value (1.42) was one of five in one uterine horn from the superovulated animal that carried her embryos for the full 35 days. In no other case were more than two embryos carried in any one uterine horn. The demarcation of two-thirds and one-third of normal value was used to distinguish heterozygous and homozygous recessive embryos, respectively. Thus, heterozygous embryos would be expected to have values between 0.91 and 1.83 units/mg protein and homozygous recessives would have values $<0.91$ units $/ \mathrm{mg}$ protein.

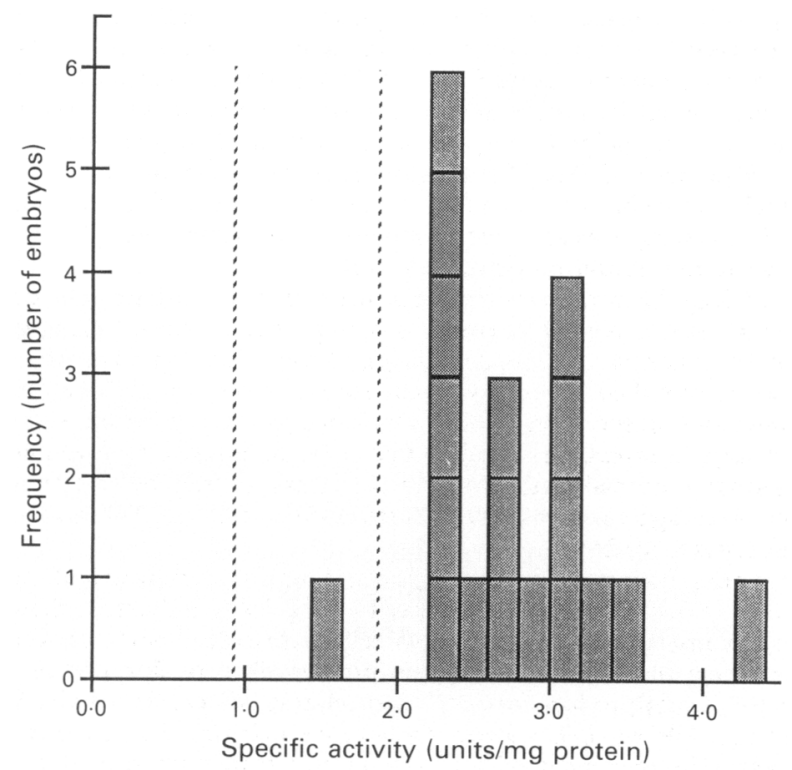

Fig. 1. Distribution of uridine monophosphate synthase activity among 35-day bovine embryos from normal $\times$ normal matings. Dashed lines designate one-third and two-thirds of normal activity. All embryos from these matings are obligatorily normal.

In 35-day embryos from heterozygote $\times$ heterozygote matings, the mean UMP synthase activity of 1.51 units $/ \mathrm{mg}$ protein (standard deviation of 0.80 units $/ \mathrm{mg}$ protein) was significantly lower $(P<0.01)$ than the mean activity of the obligatorily normal embryos (Fig. 2$)$. The coefficient of variation of $53 \%$ was also larger than observed for obligatorily normal embryos supporting the hypothesis that more than one genotype was represented among embryos from heterozygote $\times$ heterozygote matings. Following our classification criteria, embryos were found in three 
non-overlapping groups; ranges (means \pm s.e.m.) were as follows: five putative normal embryos with $2 \cdot 25-3.49$ units/mg protein $(2.64 \pm 0.22)$; ten putative heterozygous embryos with 1.08 to 1.41 units/mg protein $(1.22 \pm 0.15)$; three putative homozygous recessives with 0.47 to 0.68 units/ $\mathrm{mg}$ protein $(0.60 \pm 0.28)$. Furthermore, the distribution of 5:10:3 was not statistically different from the expected ratio of $1: 2: 1$ for heterozygote $\times$ heterozygote matings. The results demonstrate that the homozygous recessive genotype is indeed conceived and can be carried for 35 days.

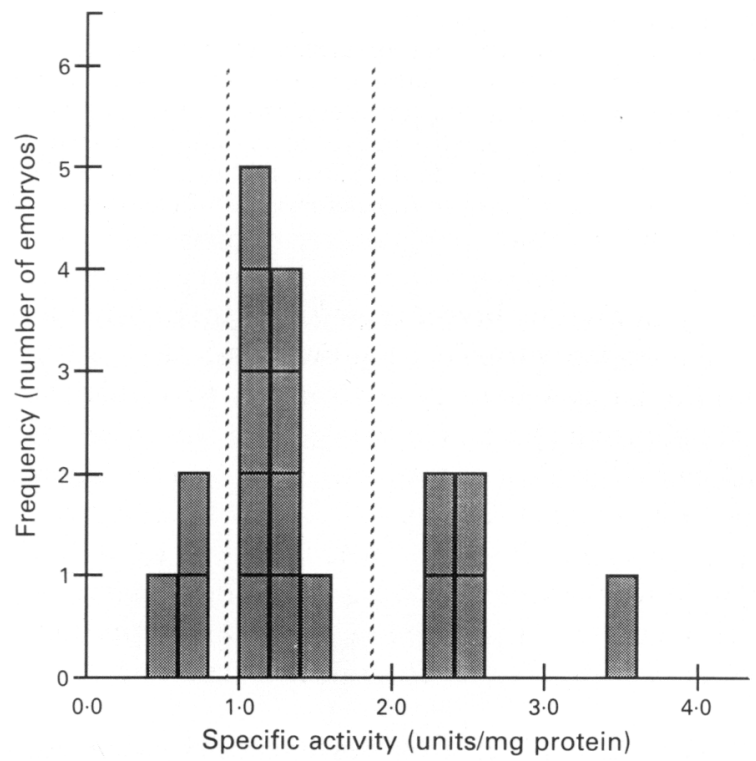

Fig. 2. Distribution of uridine monophosphate synthase activity among 35-day bovine embryos from heterozygote $\times$ heterozygote matings. Dashed lines designate one-third to two-thirds of normal activity. Putative (homozygous) normal embryos have activity > two-thirds normal; putative heterozygotes have activity between one-third and two-thirds normal; and putative homozygous recessives have activity < one-third normal.

Considering all embryos, genotype (obligatory normal, putative normal, putative heterozygote and putative homozygous recessive) accounted for $75 \%$ of the variation in activity of UMP synthase. Table 1 reports their developmental characteristics. Genotype accounted for $33 \%$ of the variation in mass, $35 \%$ of the variation in greatest length and $30 \%$ of the variation in contour length. Differences between genotypes for mass, greatest length and contour length were all significant $(P<0.01)$. While the putative homozygous recessives were smaller by all criteria, this was primarily due to one embryo that may have been degenerating. It is not known whether the low UMP synthase activity in this embryo is a cause of or a result of the degeneration process. The mass and size of the obligatorily normal embryos were smaller than for the putative normal embryos; crowding (five embryos in one horn) may account for this observation. The mass, greatest length and contour lengths were similar to values reported for individual 33- and 37-day bovine embryos (350 and $906 \mathrm{mg} ; 1.28$ and $1.83 \mathrm{~cm} ; 3.44$ and $4.31 \mathrm{~cm}$, respectively) (Winters et al., 1942). From measurements on 37 embryos, the correlation between greatest length and contour length was $0 \cdot 88$, supporting the expected strong association between these measurements of size. Mass was also positively correlated with greatest length $(r=0.88)$ and contour length $(r=0.82)$. Correlations between activity of UMP synthase and size measurements were near zero when estimated from all embryos. This was expected in as much as activity is expressed per mg protein in order to normalize for size. 
Table 1. Developmental characteristics* of 35-day bovine embryos

\begin{tabular}{lccc}
\hline Genotype $\dagger(n)$ & $\begin{array}{c}\text { Mass } \\
(\mathrm{mg})\end{array}$ & $\begin{array}{c}\text { Greatest length } \\
(\mathrm{cm})\end{array}$ & $\begin{array}{c}\text { Contour length } \\
(\mathrm{cm})\end{array}$ \\
\hline Obligatory normal (19) & $361 \pm 32$ & $1.46 \pm 0.04$ & $4 \cdot 14 \pm 0.11$ \\
Putative normal (5) & $573 \pm 58$ & $1 \cdot 72 \pm 0.08$ & $4 \cdot 71 \pm 0.22$ \\
Putative heterozygote (10) & $508 \pm 41$ & $1.64 \pm 0.06$ & $4.53 \pm 0.16$ \\
Putative homozygote (3) & $346 \pm 75$ & $1.27 \pm 0.11$ & $3.58 \pm 0.28$ \\
\hline *Values are least squares means \pm s.e.m. \\
†Genotypes with respect to deficiency of uridine monophosphate synthase were \\
designated as follows: obligatory normal, all embryos from normal $\times$ normal \\
matings; putative normal, embryos from heterozygote $\times$ heterozygote matings with \\
> two-thirds normal activity; putative heterozygote, embryos from heterozygote $\times$ \\
heterozygote matings with one-third to two-thirds normal activity; putative \\
homozygote (recessive), embryos from heterozygote $\times$ heterozygote matings with \\
<one-third normal activity.
\end{tabular}

Among the obligatorily normal embryos, crowding significantly affected mass and greatest length $(P<0.01)$ and had a tendency to affect contour length $(P<0 \cdot 10)$ (Table 2$)$. In retrospect, the decision to allow one normal cow to carry her own superovulated embryos compromised one objective of evaluating development of putative heterozygotes and putative homozygous recessives. The obligatorily normal embryo with the least activity of UMP synthase was the smallest obligatorily normal embryo. For obligatorily normal embryos, the correlation of UMP synthase activity was 0.60 with greatest length $(P<0.01), 0.42$ with mass $(P>0.05)$, and 0.41 with contour length $(P>0.05)$. Apparent inconsistency between different estimates of the association between size and activity of UMP synthase is a function of few observations and influence of one or two aberrant embryos, which apparently resulted from uterine crowding.

Table 2. Crowding influence on developmental characteristics* of obligatory normal 35-day bovine embryos

\begin{tabular}{lcccc}
\hline $\begin{array}{l}\text { Embryos/ } \\
\text { recipient }\end{array}$ & Embryos & $\begin{array}{c}\text { Mass } \\
(\mathrm{mg})\end{array}$ & $\begin{array}{c}\text { Greatest length } \\
(\mathrm{cm})\end{array}$ & $\begin{array}{c}\text { Contour length } \\
(\mathrm{cm})\end{array}$ \\
\hline 1 & $44^{\dagger}$ & $413 \pm 47$ & $1 \cdot 48 \pm 0.05$ & $4 \cdot 26 \pm 0 \cdot 17$ \\
2 & $6^{+}$ & $468 \pm 37$ & $1.62 \pm 0.04$ & $4 \cdot 37 \pm 0 \cdot 14$ \\
$>2$ & 9 & $285 \pm 27$ & $1 \cdot 34 \pm 0.03$ & $3.94 \pm 0 \cdot 12$ \\
\hline
\end{tabular}

*Values are least squares means \pm s.e.m.

$\dagger$ Three embryos for mass.

†Five embryos for mass.

Homozygotes for deficiency of UMP synthase are conceived and can survive for 35 days of gestation. On average, for this age, these putative homozygous recessives are not as large as expected. Any altered development would be a prelude to the embryonic mortality deduced in a previous study (Shanks \& Robinson, 1989). However, developmental retardation from a cause other than UMP synthase deficiency may also lead to lower UMP synthase activity.

The authors gratefully acknowledge D. Hornickel and C. Keim (Sunshine Genetics, Whitewater, WI, USA) for all non-surgical embryo transfers made on Days 7 or 8 . Support for this work was from Hatch Project ILLU-35-0307 and USDA grant AG88-37242-3846.

\section{References}

Bradford, M. (1976) A rapid and sensitive method for the quantitation of microgram quantities of protein utilizing the principle of protein-dye binding. Anal. Biochem. 72, 248-254. 
Harden, K.K. \& Robinson, J.L. (1987) Deficiency of UMP synthase in dairy cattle: A model for hereditary orotic aciduria. J. Inher. Metab. Dis. 10, 20I-209.

Jones, L.R., Harden, K.K., Bragg, D.S. \& Robinson, J.L. (1986) Influence of age, sex, lactational state and exogenous growth hormone on erythrocyte UMP synthase in dairy cattle. Comp. Biochem. Physiol. 84B, 489-495.

Robinson, J.L., Dombrowski, D.B., Harpestad, G.W. \& Shanks, R.D. (1984) Detection and prevalence of UMP synthase deficiency among dairy cattle. $J$. Heredity 75, 277-280.

Robinson, J.L., McCoy, G.C. \& Shanks, R.D. (1989) Detection of uridine monophosphate synthase in bovine embryos. J. Dairy Sci. 72, Suppl. 1, 400.

Salisbury, G.W., Hart, R.G. \& Lodge, J.R. (1977) The spermatozoan genome and fertility. Am. J. Obstet. Gynecol. 128, 342-350.

Shanks, R.D. (1990) Reproductive consequences of deficiency of uridine monophosphate synthase in Holstein cattle. Am. J. Vet. Res. 51, 800-802.
Shanks, R.D. \& Robinson, J.L. (1989) Embryonic mortality attributed to inherited deficiency of uridine monophosphate synthase. J. Dairy Sci. 72, 3035-3039.

Shanks, R.D., Dombrowski, D.B., Harpestad, G.W. \& Robinson, J.L. (1984) Inheritance of UMP synthase in dairy cattle. $J$. Heredity $75,337-340$.

Shanks, R.D., Braggs, D.S.A. \& Robinson, J.L. (1987) Incidence and inheritance of deficiency for uridine monophosphate synthase in Holstein bulls. J. Dairy Sci. 70, 1893-1897.

Shanks, R.D., Popp, R.G., McCoy, G.C., Nelson, D.R. \& Robinson, J.L. (1990) Identification of the homozygous recessive genotype for the deficiency of uridine monophosphate synthase in 36-day bovine embryos. J. Dairy Sci. 73, Suppl. 1, 253.

Winters, L.M., Green, W.W. \& Comstock, R.E. (1942) Prenatal development of the bovine. Minnesota Technical Bulletin (University of Minnesota Agricultural Experiment Station) 151, $1-50$.

Received 22 April 1991 